\title{
Screening for Barrett's Esophagus: Balancing Clinical Value and Cost-effectiveness
}

\author{
Amit Patel $^{1 *}$ and C Prakash Gyawali ${ }^{2}$ \\ ${ }^{I}$ Division of Gastroenterology, Duke University School of Medicine, and the Durham Veterans Affairs Medical Center, Durham, NC, USA; and \\ ${ }^{2}$ Division of Gastroenterology, Washington University School of Medicine, St Louis, MO, USA
}

\begin{abstract}
In predisposed individuals with long standing gastroesophageal reflux disease (GERD), esophageal squamous mucosa can transform into columnar mucosa with intestinal metaplasia, commonly called Barrett’s esophagus (BE). Barrett's mucosa can develop dysplasia, which can be a precursor for esophageal adenocarcinoma (EAC). However, most EAC cases are identified when esophageal symptoms develop, without prior BE or GERD diagnoses. While several gastrointestinal societies have published BE screening guidelines, these vary, and many recommendations are not based on high quality evidence. These guidelines are concordant in recommending targeted screening of predisposed individuals (eg, long standing GERD symptoms with age $>50$ years, male sex, Caucasian race, obesity, and family history of BE or EAC), and against population based screening, or screening of GERD patients without risk factors. Targeted endoscopic screening programs provide earlier diagnosis of high grade dysplasia and EAC, and offer potential for endoscopic therapy, which can improve prognosis and outcome. On the other hand, endoscopic screening of the general population, unselected GERD patients, patients with significant comorbidities or patients with limited life expectancy is not cost-effective. New screening modalities, some of which do not require endoscopy, have the potential to reduce costs and expand access to screening for BE.
\end{abstract}

(J Neurogastroenterol Motil 2019;25:181-188)

Key Words

Adenocarcinoma of esophagus; Barrett's esophagus; Gastroesophageal reflux

\section{Introduction}

Gastroesophageal reflux disease (GERD) typically presents with heartburn and acid regurgitation, afflicting an estimated 18$28 \%$ of the North American population. ${ }^{1}$ In $5-15 \%$ of chronic GERD, esophageal mucosa can transform from normal squamous to columnar mucosa with intestinal characteristics (intestinal metaplasia or Barrett's esophagus [BE] $)^{2-4} \mathrm{BE}$ confers an estimated 10 -fold increase in risk for esophageal adenocarcinoma (EAC) above the general population, prompting screening and surveillance protocols. Time trends demonstrate that the incidence of EAC has continued to escalate in comparison to other cancers (colon, lung, and breast), and that the rising incidence cannot be explained on the basis of increased identification of previously undiagnosed EAC. ${ }^{5}$

Gastroenterology societies across the globe have published BE screening recommendations (Table). ${ }^{6-12}$ However, these recommendations are not always based on high-quality evidence. ${ }^{13}$ In fact, a systematic analysis and critical appraisal of $8 \mathrm{BE}$ practice guidelines published between 2005 and 2013 found that the majority of guidelines failed to meet the Appraisal of Guidelines for Research and Evaluation II (AGREE II) domains and most recommendations

Received: September 13, 2018 Revised: November 25, 2018 Accepted: December 8, 2018

(.) This is an Open Access article distributed under the terms of the Creative Commons Attribution Non-Commercial License (http://creativecommons. org/licenses/by-nc/4.0) which permits unrestricted non-commercial use, distribution, and reproduction in any medium, provided the original work is properly cited.

*Correspondence: Amit Patel, MD

Division of Gastroenterology, Duke University School of Medicine, 10207 Cerny St, Suite 210, Raleigh, NC 27617, USA

Tel: +1-919-684-1816, Fax: +1-919-479-2664, E-mail: amit.patel@duke.edu 


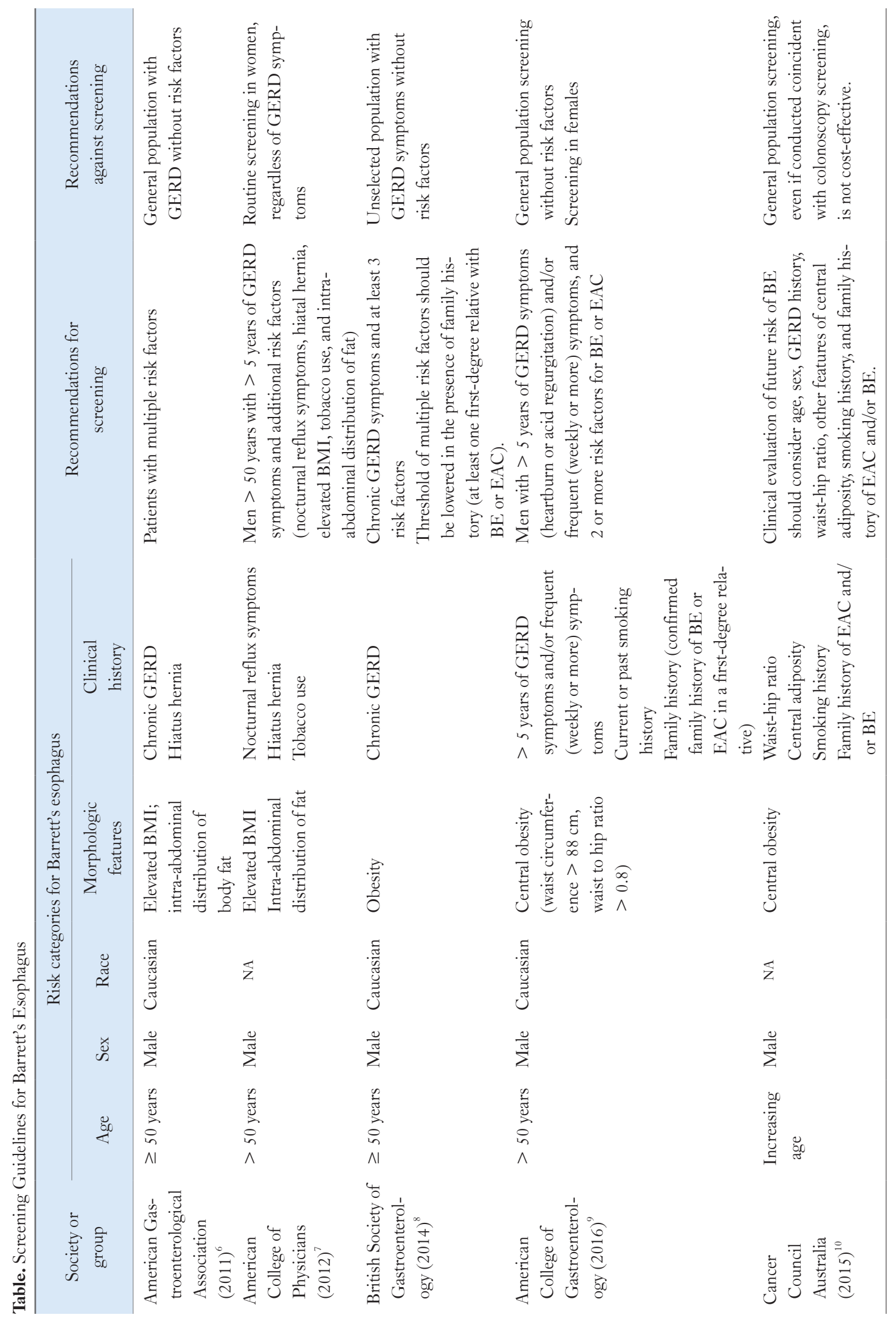




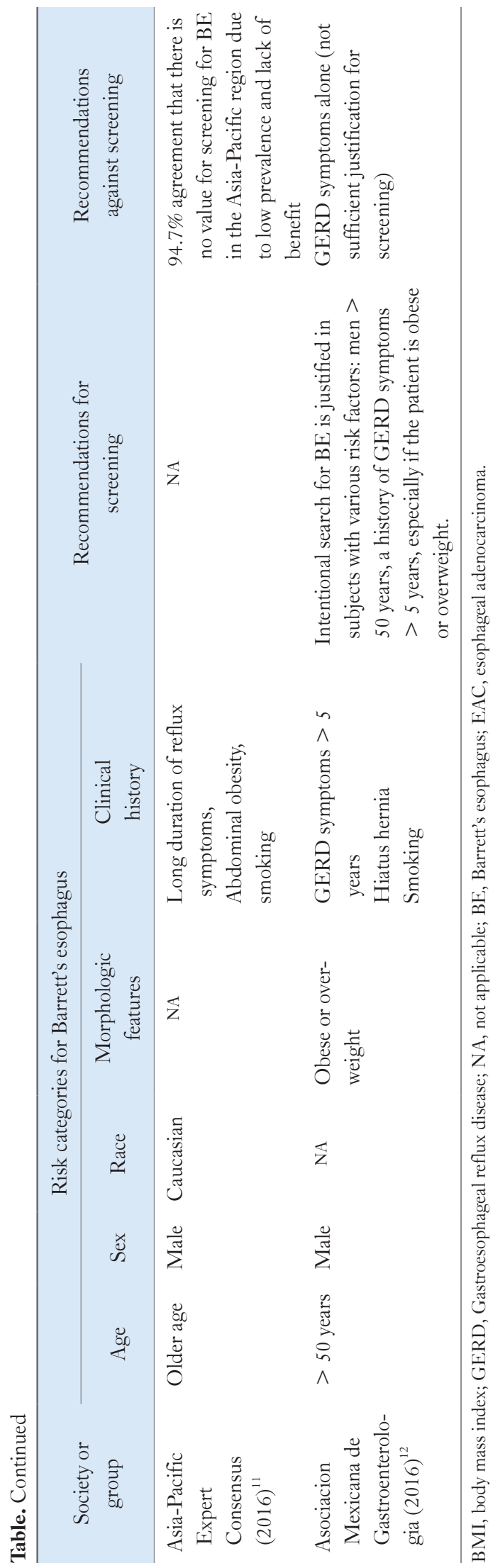

were level B (49\%) or C (45\%) quality evidence. ${ }^{14}$ Notably, $40 \%$ of EAC cases have no prolonged reflux history, ${ }^{15}$ and $<5 \%$ carry a prior diagnosis of $\mathrm{BE}{ }^{16}$ Within this context, this review addresses the balance between the clinical value and cost-effectiveness of $\mathrm{BE}$ screening. ${ }^{17}$

\section{Clinical Value of Screening}

In predisposed individuals, $\mathrm{BE}$ progresses through low-grade dysplasia (LGD) and high-grade dysplasia (HGD) to EAC. Supporting this concept, the annual risk of progression to EAC is higher in HGD $(6.0-7.0 \%)^{18,19}$ compared to community LGD diagnoses $(0.4-0.6 \%)^{20,21}$ or non-dysplastic BE (0.1-0.3\%, which has decreased in recent decades from previous higher estimated ranges). ${ }^{22-27}$

Data suggest superior survival outcomes when EAC is diagnosed in pre-existing BE. In a study based on Surveillance, Epidemiology, and End Results and linked Medicare data, patients diagnosed with $\mathrm{EAC}$ in the setting of pre-existing $\mathrm{BE}$ had overall lower stage $\mathrm{EAC}$ and superior overall survival compared to those diagnosed with EAC without pre-existing $\mathrm{BE}$ (hazard ratio, 0.56; 95\% CI, 0.50-0.61 that persisted in an adjusted model with hazard ratio, $0.72 ; 95 \% \mathrm{CI}, 0.65-0.80) .{ }^{28}$ Likewise, meta-analysis also demonstrated a survival advantage for EAC detected from screening protocols compared to symptom-based EAC diagnosis (relative risk of mortality, $0.73 ; 95 \% \mathrm{CI}, 0.57-0.94)$, associated with earlierstage EAC diagnosis. ${ }^{29}$

However, adjustment for lead- and length-time biases in these studies substantially attenuated these reported survival benefits. Nonetheless, data from a large Veterans Affairs cohort ( $>8500$ cases of $\mathrm{EAC}$ ) suggests that the observed survival benefit in EAC in the setting of pre-existing $\mathrm{BE}$ (hazard ratio, $0.69 ; 95 \% \mathrm{CI}, 0.61$ 0.80 ) stems largely from the earlier stage of $\mathrm{EAC}$ at diagnosis, finding no evidence for lead-time or length-time biases in their findings. ${ }^{30}$ Another report demonstrates that when symptoms prompt advanced $\mathrm{EAC}$ diagnosis without prior knowledge of BE, 5-year survival is abysmal $(<3 \%)$, while early $\mathrm{EAC}$ has a better prognosis ( $>20 \% 5$-year survival). ${ }^{31}$

Consequently, screening can identify dysplastic BE or early EAC — when endoscopic ablative therapies could reduce mortality and prolong life while remaining cost-effective. ${ }^{6,32-36}$ When applied to dysplastic BE, radiofrequency ablation (RFA), photodynamic therapy, and endoscopic mucosal resection reduce progression to EAC. ${ }^{36-38}$ For example, in a multicenter sham-controlled trial of patients with dysplastic $\mathrm{BE}$, progression to $\mathrm{EAC}$ was significantly 
lower with RFA treatment (1.2\% vs $9.3 \%, P=0.045) .{ }^{37}$ Thus, BE screening programs have the potential to impact the natural history of $\mathrm{BE}$ in select settings.

On meta-analysis, long-standing GERD symptoms increase the risk of long-segment $\mathrm{BE} 5$-fold, ${ }^{39}$ yet $\mathrm{BE}$ is associated with esophageal hyposensitivity despite high reflux burden. ${ }^{40,41}$ Thus, heartburn symptoms diminish as BE develops, and focusing solely on heartburn may miss these hyposensitive patients. Supporting this concept, $\mathrm{BE}$ is reported in asymptomatic individuals, with a prevalence of $1.3-1.6 \%$ in European population studies, ${ }^{42,43}$ and 5.6-6.8\% in United States populations. ${ }^{2,44}$ The frequency of identification of $\mathrm{BE}$ was similar between patients with heartburn $(8.3 \%)$ and without heartburn $(5.6 \%, P=0.1)$ among 1000 patients enrolled from a screening colonoscopy cohort, although the likelihood of long-segment $\mathrm{BE}$ was higher when heartburn was present (2.6\% vs $0.36 \%, P=0.01)^{2}$. Further, GERD can present with atypical symptoms (chest pain, cough, sore throat, and laryngitis) or regurgitation without heartburn, and acid suppressive therapy can modify or resolve symptoms; $\mathrm{BE}$ and $\mathrm{EAC}$ are identified in these patients as well. ${ }^{45,46}$ Consequently, if heartburn were the sole symptom prompting screening, BE in atypical GERD, hyposensitive, or asymptomatic populations would likely be missed. For a $\mathrm{BE}$ screening program to be successful, all individuals with risk factors in the setting of documented evidence of GERD ("proven GERD," includes erosive esophagitis, biopsy-proven intestinal metaplasia, abnormal $\mathrm{pH}$ study, and peptic strictures) ${ }^{47}$ may need to be targeted, regardless of presenting symptoms. However, screening of the general population and of low-risk groups is clearly not cost-effective and not recommended (Table).

\section{Costs of Screening}

Beyond the relatively rare but real medical risks associated with endoscopy and endoscopic therapies, the resources utilized for BE screening and therapy are tremendous. In a study conducted among the West Virginia Medicaid population in the late 1990s, limited by its prevalence-based approach prior to the widespread use of endoscopic ablative therapies, and exclusion of Medicare-eligible recipients, BE patients incurred $21.2 \%$ higher costs than GERD patients and $62.4 \%$ higher costs than the general Medicaid population. ${ }^{48}$ In this study, the authors estimated that about two-thirds of the total medical costs in this population stemmed from pharmacy costs. Another cost analysis performed at the Durham Veterans Affairs Medical Center in North Carolina prior to the widespread use of ablative approaches suggested that the annual cost of outpa- tient care for BE approximated United States dollar (\$) 1241, with medications accounting for over half of total costs. ${ }^{49}$ The authors found that these monthly medication costs among patients with $\mathrm{BE}$ approximated those for patients with insulin-requiring diabetes mellitus in patients at this medical center. However, endoscopic ablative BE therapies carry risks as well as the need for more frequent endoscopies, incurring higher resource utilization compared to GERD without BE. ${ }^{48,49}$ A European study, which included 6000 GERD patients from Germany, Austria, and Switzerland, found that a diagnosis of $\mathrm{BE}$ resulted in more than double the yearly direct medical costs compared to those with non-erosive reflux disease (Euros 631 vs 270), again driven primarily by increased medication costs. $^{50}$

The highest-quality cost estimates of $\mathrm{BE}$ screening for GERD patients fall within a range of $\$ 10 \mathrm{~K}-\$ 25 \mathrm{~K}$ per life-year saved, comparing favorably in cost-effectiveness with other accepted cancer screening strategies. ${ }^{51-55}$ These estimates are limited in methodology, as there is a paucity of randomized trial evidence to accurately develop cost estimates, and most available studies are limited by lack of consideration of newer endoscopic ablative techniques, such as RFA. ${ }^{56}$ Incorporating endoscopic therapy for dysplasia and intramucosal EAC, this estimate shifts to around $\$ 22 \mathrm{~K},{ }^{55}$ demonstrating how dysplasia found on BE screening can prompt endoscopic ablative therapies, further improving cost-effectiveness over continued surveillance or esophagectomy. ${ }^{36,57-59}$ In contrast, performing upper endoscopy for upper gastrointestinal cancer screening in the general population at the time of screening colonoscopy costs $\$ 116 \mathrm{~K}$ per quality-adjusted life-year when compared with no screening-significantly higher than targeted screening, despite the reduced costs of performance at the time of colonoscopy. ${ }^{60}$

\section{Limitations of Screening}

Endoscopic screening for BE has shortcomings. Adherence to screening recommendations is suboptimal; only $35 \%$ of practitioners reported screening all chronic GERD patients with endoscopy in one survey. ${ }^{61,62} \mathrm{EAC}$ is predominantly diagnosed without prior GERD or $\mathrm{BE},{ }^{16}$ and the majority with $\mathrm{BE}$ derive limited benefit from surveillance directed by findings on screening. ${ }^{63,64}$ Nationwide population-based work from Denmark suggests that the absolute annual risk of EAC among $\mathrm{BE}$ is $0.12 \%$, lower than previously suspected. ${ }^{23}$ Moreover, work from the UK indicates that among $\mathrm{BE}$, only $1.9 \%$ will die of esophageal cancer within 10 years; the remainder succumb more frequently to other diseases, such as ischemic coronary disease. ${ }^{63}$ 
The yield of endoscopic screening improves when adequate time is spent inspecting the esophagus and the identified BE segments, which increases detection of HGD and EAC. ${ }^{65}$ There is inter-observer variation in the histopathologic diagnosis of dysplasia in BE, particularly LGD, necessitating further biopsy review by expert pathologists before confirmation of dysplasia. ${ }^{66}$ Going forward, alternative or adjunctive screening tools under development (such as transnasal endoscopy, sponge devices, ${ }^{67}$ biomarkers, ${ }^{68}$ breath testing, and genetic testing ${ }^{69}$ ) have the potential to improve costeffectiveness and potentially expand screening to populations that may not have easy access to endoscopy and sedation. Specifically, transnasal endoscopy (as compared to traditional sedated transoral endoscopy) may be performed in the outpatient clinic setting without sedation, leading to superior patient acceptability, safety, and cost-effectiveness. ${ }^{70}$ The cytosponge device consists of a spherical mesh compressed within a gelatinous capsule, that dissolves in the stomach upon being swallowed. This mesh then samples the esophagus as it is withdrawn orally via string, with immunohistochemical staining for the Trefoil Factor 3 biomarker performed on the obtained specimen. Multicenter data suggest sensitivity of $80 \%$ (higher for long-segment BE) and specificity of $>90 \%$ for a diagnosis of $\mathrm{BE}$ with the cytosponge device. ${ }^{71}$

\section{Targeted Screening for Barrett's Esophagus}

Given these benefits, limitations, and costs, screening programs for BE among selected populations has value - the cardinal question becomes "who" to screen and "how" to screen.

Guidelines are concordant in recommending targeted screening when risk factors are identified (age $>50$ years, male sex, Caucasian race, long-standing GERD, hiatal hernia, elevated body mass index, central obesity, smoking history, family history of $\mathrm{BE}$ or EAC) $)^{6,9}$ but "not" in the general asymptomatic or GERD populations (Table). ${ }^{72}$ In the absence of other risk factors, females are generally not targeted for screening for $\mathrm{BE}$, since the risk of $\mathrm{EAC}$ in females approximates the risk of breast cancer in males. ${ }^{7}$ Since chronic heartburn predicts long-segment $\mathrm{BE},{ }^{2,39,73}$ heartburn in the presence of other risk factors should trigger BE screening. In this context, expanding screening to proven GERD with any presenting symptom (past evidence of erosive esophagitis, peptic stricture, or abnormal esophageal reflux burden $)^{47}$ in patients fulfilling other risk categories has potential to increase the diagnostic yield of screening.

\section{Conclusions}

Education of clinicians - gastroenterologists as well as primary care providers - in recognizing GERD symptoms and risk factors for $\mathrm{BE} / \mathrm{EAC}$ can improve screening of susceptible populations. ${ }^{74}$ Screening should target high-risk individuals with GERD symptoms, but not with limited life expectancy (proposed as $<5$ years) ${ }^{72}$ or profound comorbidities. While the focus remains on typical reflux symptoms, clinicians should consider screening patients with proven GERD with risk factors for BE/EAC. New modalities under investigation may decrease the costs associated with $\mathrm{BE}$ screening and expand access to screening. The selective use of endoscopic screening when risk factors for BE/EAC are identified (with adequate time spent inspecting the esophagus), the use of endoscopic ablative therapies in dysplastic $\mathrm{BE}$, and prospective outcome analysis can maximize cost-effective clinical outcomes.

\section{Take-Home Points}

- BE represents a complication of GERD that confers an increased risk for EAC.

- Because endoscopic ablative therapies can reduce the progression of dysplastic BE to EAC, screening programs can impact the natural history of $\mathrm{BE}$.

- BE screening in selected at-risk populations compares favorably in cost-effectiveness with other accepted cancer screening programs.

- However, screening of the general population for BE or unselected patients with GERD is neither cost-effective nor recommended by consensus guidelines.

- Instead, guidelines recommend targeted screening for BE in the presence of risk factors - including age $>50$ years, male sex, Caucasian race, long-standing GERD, hiatal hernia, elevated body mass index, central obesity, smoking, and family history.

- Looking forward, alternative screening tools may improve the cost-effectiveness of and enhance access to screening for BE.

Financial support: None.

Conflicts of interest: None.

Author contributions: Amit Patel and C Prakash Gyawali con- 
tributed equally to the drafting and revision of this manuscript.

\section{References}

1. El-Serag HB, Sweet S, Winchester CC, Dent J. Update on the epidemiology of gastro-oesophageal reflux disease: a systematic review. Gut 2014;63:871-880.

2. Rex DK, Cummings OW, Shaw M, et al. Screening for Barrett's esophagus in colonoscopy patients with and without heartburn. Gastroenterology 2003;125:1670-1677.

3. Sharma P. Review article: prevalence of Barrett's oesophagus and metaplasia at the gastro-oesophageal junction. Aliment Pharmacol Ther 2004;20(suppl 5):48-54; discussion 61-62.

4. Johansson J, Håkansson HO, Mellblom L, et al. Prevalence of precancerous and other metaplasia in the distal oesophagus and gastro-oesophageal junction. Scand J Gastroenterol 2005;40:893-902.

5. Pohl H, Welch HG. The role of overdiagnosis and reclassification in the marked increase of esophageal adenocarcinoma incidence. J Natl Cancer Inst 2005;97:142-146.

6. Spechler SJ, Sharma P, Souza RF, Inadomi JM, Shaheen NJ. American gastroenterological association technical review on the management of Barrett's esophagus. Gastroenterology 2011;140:e18-e52.

7. Shaheen NJ, Weinberg DS, Denberg TD, et al. Upper endoscopy for gastroesophageal reflux disease: best practice advice from the clinical guidelines committee of the American college of physicians. Ann Intern Med 2012;157:808-816.

8. Fitzgerald RC, di Pietro M, Ragunath K, et al. British society of gastroenterology guidelines on the diagnosis and management of Barrett's oesophagus. Gut 2014;63:7-42.

9. Shaheen NJ, Falk GW, Iyer PG, Gerson LB. ACG clinical guideline: diagnosis and management of Barrett's esophagus. Am J Gastroenterol 2016;111:30-50.

10. Whiteman DC, Appleyard M, Bahin FF, et al. Australian clinical practice guidelines for the diagnosis and management of Barrett's esophagus and early esophageal adenocarcinoma. J Gastroenterol Hepatol 2015;30:804820.

11. Fock KM, Talley N, Goh KL, et al. Asia-pacific consensus on the management of gastro-oesophageal reflux disease: an update focusing on refractory reflux disease and Barrett's oesophagus. Gut 2016;65:14021415.

12. Huerta-Iga F, Bielsa-Fernández MV, Remes-Troche JM, et al. Diagnosis and treatment of gastroesophageal reflux disease: recommendations of the asociacion Mexicana de gastroenterologia. Rev Gastroenterol Mex 2016;81:208-222.

13. Sharma P, Katzka DA, Gupta N, et al. Quality indicators for the management of Barrett's esophagus, dysplasia, and esophageal adenocarcinoma: international consensus recommendations from the American gastroenterological association aymposium. Gastroenterology 2015;149:15991606.

14. Feuerstein JD, Castillo NE, Akbari M, et al. Systematic analysis and critical appraisal of the quality of the scientific evidence and conflicts of interest in practice guidelines (2005-2013) for Barrett's ssophagus. Dig Dis Sci 2016;61:2812-2822.

15. Lagergren J, Bergstrom R, Lindgren A, Nyrét O. Symptomatic gastroesophageal reflux as a risk factor for esophageal adenocarcinoma. $\mathrm{N}$ Engl J Med 1999;340:825-831.

16. Dulai GS, Guha S, Kahn KL, Gornbein J, Weinstein WM. Preoperative prevalence of Barrett's esophagus in esophageal adenocarcinoma: a systematic review. Gastroenterology 2002;122:26-33.

17. Camilleri M, Katzka DA. Enhancing high value care in gastroenterology practice. Clin Gastroenterol Hepatol 2016;14:1376-1384.

18. Rastogi A, Puli S, El-Serag HB, Bansal A, Wani S, Sharma P. Incidence of esophageal adenocarcinoma in patients with barrett's esophagus and high-grade dysplasia: a meta-analysis. Gastrointest Endosc 2008;67:394398.

19. Spechler SJ. Barrett esophagus and risk of esophageal cancer: a clinical review. JAMA 2013;310:627-636.

20. Wani S, Falk GW, Post J, et al. Risk factors for progression of lowgrade dysplasia in patients with Barrett's esophagus. Gastroenterology 2011;141:1179-1186, e1.

21. Singh S, Manickam P, Amin AV, et al. Incidence of esophageal adenocarcinoma in Barrett's esophagus with low-grade dysplasia: a systematic review and meta-analysis. Gastrointest Endosc 2014;79:897-909, e4.

22. Bhat $\mathrm{S}$, Coleman HG, Yousef $\mathrm{F}$, et al. Risk of malignant progression in Barrett's esophagus patients: results from a large population-based study. J Natl Cancer Inst 2011;103:1049-1057.

23. Hvid-Jensen F, Pedersen L, Drewes AM, Søensen HT, Funch-Jensen P. Incidence of adenocarcinoma among patients with Barrett's esophagus. N Engl J Med 2011;365:1375-1383.

24. Desai TK, Krishnan K, Samala N, et al. The incidence of oesophageal adenocarcinoma in non-dysplastic Barrett's oesophagus: a meta-analysis. Gut 2012;61:970-976.

25. Pereira AD, Chaves P. Low risk of adenocarcinoma and high-grade dysplasia in patients with non-dysplastic Barrett's esophagus: results from a cohort from a country with low esophageal adenocarcinoma incidence. United European Gastroenterol J 2016;4:343-352.

26. Peters Y, Honing J, Kievit W, et al. Incidence of progression of persistent non-dysplastic Barrett's esophagus to malignancy. Clin Gastroenterol Hepatol Published Online First: 11 Sep 2018. doi: 10.1016/ j.cgh.2018.08.033

27. Hamade N, Vennelaganti S, Parasa S, et al. Lower annual rate of progression of short-segment vs long-segment Barrett's esophagus to esophageal adenocarcinoma. Clin Gastroenterol Hepatol Published Online First: 7 Aug 2018. doi: 10.1016/j.cgh.2018.07.008

28. Tramontano AC, Sheehan DF, Yeh JM, et al. The impact of a prior diagnosis of Barrett's esophagus on esophageal adenocarcinoma survival. Am J Gastroenterol 2017;112:1256-1264.

29. Codipilly DC, Chandar AK, Singh S, et al. The effect of endoscopic surveillance in patients with Barrett's esophagus: a systematic review and meta-analysis. Gastroenterology 2018;154:2068-2086, e5.

30. Wenker TN, Tan MC, Liu Y, El-serag HB, Thrift AP. Prior diagnosis of Barrett's esophagus is infrequent, but associated with improved esophageal adenocarcinoma survival. Dig Dis Sci 2018;63:3112-3119. 
31. Hur C, Miller M, Kong CY, et al. Trends in esophageal adenocarcinoma incidence and mortality. Cancer 2013;119:1149-1158.

32. Fountoulakis A, Zafirellis KD, Dolan K, Dexter SP, Martin IG, SueLing HM. Effect of surveillance of Barrett's oesophagus on the clinical outcome of oesophageal cancer. Br J Surg 2004;91:997-1003.

33. Cooper GS, Kou TD, Chak A. Receipt of previous diagnoses and endoscopy and outcome from esophageal adenocarcinoma: a population-based study with temporal trends. Am J Gastroenterol 2009;104:1356-1362.

34. Verbeek RE, Leenders M, Ten Kate FJ, et al. Surveillance of Barrett's esophagus and mortality from esophageal adenocarcinoma: a populationbased cohort study. Am J Gastroenterol 2014;109:1215-1222.

35. Kastelein F, van Olphen SH, Steyerberg EW, Spaander MC, Bruno MJ. Impact of surveillance for Barrett's oesophagus on tumour stage and survival of patients with neoplastic progression. Gut 2016;65:548-554.

36. Kastelein F, van Olphen S, Steyerberg EW, et al. Surveillance in patients with long-segment Barrett's oesophagus: a cost-effectiveness analysis. Gut 2015;64:864-871.

37. Shaheen NJ, Sharma P, Overholt BF, et al. Radiofrequency ablation in Barrett's esophagus with dysplasia. N Engl J Med 2009;360:2277-2288.

38. Small AJ, Araujo JL, Leggett CL, et al. Radiofrequency ablation is associated with decreased neoplastic progression in patients with Barrett's esophagus and confirmed low-gradedysplasia. Gastroenterology 2015;149:567-576, e3.

39. Taylor JB, Rubenstein JH. Meta-analyses of the effect of symptoms of gastroesophageal reflux on the risk of Barrett's esophagus. Am J Gastroenterol 2010;105:1729, 1730-1737.

40. Byrne PJ, Mulligan ED, O'Riordan J, Keeling PW, Reynolds JV. Impaired visceral sensitivity to acid reflux in patients with Barrett's esophagus. The role of esophageal motility. Dis Esophagus 2003;16:199-203.

41. Brandt MG, Darling GE, Miller L. Symptoms, acid exposure and motility in patients with Barrett's esophagus. Can J Surg 2004;47:47-51.

42. Ronkainen J, Aro P, Storskrubb T, et al. Prevalence of Barrett's esophagus in the general population: an endoscopic study. Gastroenterology 2005;129:1825-1831.

43. Zagari RM, Fuccio L, Wallander MA, et al. Gastro-oesophageal reflux symptoms, oesophagitis and Barrett's oesophagus in the general population: the loiano-monghidoro study. Gut 2008;57:1354-1359.

44. Hayeck TJ, Kong CY, Spechler SJ, Gazeller SJ, Hur C. The prevalence of Barrett's esophagus in the US: estimates from a simulation model confirmed by SEER data. Dis Esophagus 2010;23:451-457.

45. Locke GR 3rd, Talley NJ, Fett SL, Zinsmeiter AR, Melton LJ 3rd. Prevalence and clinical spectrum of gastroesophageal reflux: a population-based study in Olmsted County, Minnesota. Gastroenterology 1997;112:1448-1456.

46. Nason KS, Wichienkuer PP, Awais O, et al. Gastroesophageal reflux disease symptom severity, proton pump inhibitor use, and esophageal carcinogenesis. Arch Surg 2011;146:851-858.

47. Gyawali CP, Kahrilas PJ, Savarino E, et al. Modern diagnosis of GERD: the lyon consensus. Gut 2018;67:1351-1362.

48. Amonkar MM, Kalsekar ID, Boyer JG. The economic burden of Barrett's esophagus in a medicaid population. Ann Pharmacother 2002;36:605-611.
49. Eloubeidi MA, Homan RK, Martz MD, Theobald KE, Provenzale D. A cost analysis of outpatient care for patients with Barrett's esophagus in a managed care setting. Am J Gastroenterol 1999;94:2033-2036.

50. Willich SN, Nocon M, Kulig M, et al. Cost-of-disease analysis in patients with gastro-oesophageal reflux disease and Barrett's mucosa. Aliment Pharmacol Ther 2006;23:371-376.

51. Soni A, Sampliner RE, Sonnenberg A. Screening for high-grade dysplasia in gastroesophageal reflux disease: is it cost-effective? Am J Gastroenterol 2000;95:2086-2093.

52. Inadomi JM, Sampliner R, Lagergren J, Lieberman D, Fendrick AM, Vakil N. Screening and surveillance for Barrett esophagus in high-risk groups: a cost-utility analysis. Ann Intern Med 2003;138:176-186.

53. Gerson LB, Groeneveld PW, Triadafilopoulos G. Cost-effectiveness model of endoscopic screening and surveillance in patients with gastroesophageal reflux disease. Clin Gastroenterol Hepatol 2004;2:868-879.

54. Spechler SJ, Barr H. Review article: screening and surveillance of Barrett's oesophagus: what is a cost-effective framework? Aliment Pharmacol Ther 2004;19(suppl 1):49-53.

55. Benaglia T, Sharples LD, Fitzgerald RC, Lyratzopoulos G. Health benefits and cost effectiveness of endoscopic and nonendoscopic cytosponge screening for Barrett's esophagus. Gastroenterology 2013;144:62-73, e6.

56. Barbiere JM, Lyratzopoulos G. Cost-effectiveness of endoscopic screening followed by surveillance for Barrett's esophagus: a review. Gastroenterology 2009;137:1869-1876.

57. Inadomi JM, Somsouk M, Madanick RD, Thomas JP, Shaheen NJ. A cost-utility analysis of ablative therapy for Barrett's esophagus. Gastroenterology 2009;136:2101-2114, e1-e6.

58. Hur C, Choi SE, Rubenstein JH, et al. The cost effectiveness of radiofrequency ablation for Barrett's esophagus. Gastroenterology 2012;143:567575.

59. Hu Y, Puri V, Shami VM, Stukenborg GJ, Kozower BD. Comparative effectiveness of esophagectomy versus endoscopic treatment for esophageal high-grade dysplasia. Ann Surg 2016;263:719-726.

60. Gupta N, Bansal A, Wani SB, Gaddam S, Eastogi A, Sharma P. Endoscopy for upper GI cancer screening in the general population: a costutility analysis. Gastrointest Endosc 2011;74:610-624, e2.

61. Menezes A, Tierney A, Yang YX, et al. Adherence to the 2011 American gastroenterological association medical position statement for the diagnosis and management of Barrett's esophagus. Dis Esophagus 2015;28:538-546.

62. Pohl H, Robertson D, Welch HG. Repeated upper endoscopy in the medicare population: a retrospective analysis. Ann Intern Med 2014;160:154.

63. Solaymani-Dodaran M, Card TR, West J. Cause-specific mortality of people with Barrett's esophagus compared with the general population: a population-based cohort study. Gastroenterology 2013;144:1375-1383, e1.

64. Gaddam S, Singh M, Balasubramanian G, et al. Persistence of nondysplastic Barrett's esophagus identifies patients at lower risk for esophageal adenocarcinoma: results from a large multicenter cohort. Gastroenterology 2013;145:548-553, e1.

65. Gupta N, Gaddam S, Wani SB,Sansal A, Rastogi A, Sharma P. Longer 
inspection time is associated with increased detection of high-grade dysplasia and esophageal adenocarcinoma in Barrett's esophagus. Gastrointest Endosc 2012;76:531-538.

66. Wani S, Rubenstein JH, Vieth M, Bergman J. Diagnosis and management of low-grade dysplasia in barrett's esophagus: expert review from the clinical practice updates committee of the American hgstroenterological association. Gastroenterology 2016;151:822-835.

67. Kadri SR, Lao-Sirieix P, O'Donovan M, et al. Acceptability and accuracy of a non-endoscopic screening test for Barrett's oesophagus in primary care: cohort study. BMJ 2010;341:c4372.

68. Bansal A, Fitzgerald RC. Biomarkers in barrett's esophagus: role in diagnosis, risk stratification, and prediction of response to therapy. Gastroenterol Clin North Am 2015;44:373-390.

69. Buas MF, He Q, Johnson LG, et al. Germline variation in inflammation-related pathways and risk of Barrett's oesophagus and oesophageal adenocarcinoma. Gut 2017;66:1739-1747.

70. Blevins CH, Iyer PG. Putting it through the nose: the ins and outs of transnasal endoscopy. Am J Gastroenterol 2016;111:1371-1373.

71. Ross-Innes CS, Debiram-Beecham I, O’Donovan M, et al. Evaluation of a minimally invasive cell sampling device coupled with assessment of trefoil factor 3 expression for diagnosing Barrett's esophagus: a multicenter case-control study. PLoS Med 2015;12:e1001780.

72. Bennett C, Moayyedi P, Corley DA, et al. BOB CAT: a large-scale review and delphi consensus for management of Barrett's esophagus with no dysplasia, indefinite for, or low-grade dysplasia. Am J Gastroenterol 2015;110:662-682.

73. Balasubramanian G, Singh M, Gupta N, et al. Prevalence and predictors of columnar lined esophagus in gastroesophageal reflux disease (GERD) patients undergoing upper endoscopy. Am J Gastroenterol 2012;107:1655-1661.

74. Singh M, Gupta N, Gaddam S, et al. Practice patterns among U.S. gastroenterologists regarding endoscopic management of Barrett's esophagus. Gastrointest Endosc 2013;78:689-695. 